\title{
APPLICABILITY OF OCO-2 SOLAR INDUCED CHLOROPHYLL FLUORESCENCE (SIF) DATA FOR THE ESTIMATION OF PHOTOSYNTHETIC ACTIVITY IN BANGLADESH
}

\author{
Mohammad Imrul Islam*, SM Ahsan Habib, SAM Arif-Ul-Haque, Nasrin Sultana, BM Refat Faisal, \\ Hafizur Rahman and Mohammad Nur Hossain Sharifee
}

Bangladesh Space Research and Remote Sensing Organization (SPARRSO), Dhaka-1207, Bangladesh

Received: 08 July 2020

Accepted: 10 December 2020

\begin{abstract}
Orbiting Carbon Observatory-2 (OCO-2) is a new satellite of measuring concentrations of carbon, can also provide comparatively higher resolution Solar Induced Chlorophyll Fluorescence (SIF) data which has the potential to directly estimate the photosynthetic activity or gross primary production (GPP). The aim of the present study is to investigate the feasibility of using OCO-2 derived SIF data for the estimation of photosynthetic activity in Bangladesh. To verify the OCO-2 derived SIF data, the present study analyzes the relationship between OCO-2 derived SIF and Moderate Resolution Imaging Spectroradiometer (MODIS) derived GPP for different land cover types for the year 2015 using individual day pixel-based analysis. The relationship between SIF and GPP is found to be good for the mixed vegetation for the data accessed on 01 January and 02 February of 2015 and for the evergreen forest for the data accessed on 14 September of 2015. In contrast, the relationship is not found strong between SIF and GPP for most of the cases. The pixel-based spatial dissimilarity between OCO-2 and MODIS, and spatial distortions of OCO-2 footprints might be the possible reason behind the poor correlation between SIF and GPP found in the present study. Unavailability of the homogeneous OCO-2 derived SIF data in terms of spatial and temporal context is another possible reason behind the weak relationship between SIF and GPP. The sparse spatial coverage and poor relationship to the MODIS derived GPP data declines the reliability of OCO-2 derived SIF data for the estimation of photosynthetic activity in Bangladesh or in other local scale application.
\end{abstract}

Keywords: GPP; MODIS; OCO-2; Photosynthesis; Remote sensing of vegetation; SIF.

\section{INTRODUCTION}

Photosynthesis, a crucial internal process of energy generation and plant growth, functions as a significant indicator of plant health and status which plays an essential role in precision farming and proper agriculture management. Additionally, spatially and temporally explicit estimation of photosynthesis can provide global and regional terrestrial GPP which is of great importance because of its key role in the atmosphere-biosphere interactions (Cui et al., 2017; Zhang et al., 2014). Primary production is the rate of accumulation of biomass and GPP is the total amount of energy produced by vegetation through photosynthesis. Recent developments in the field of space-borne imaging spectroscopy technology and data processing have enabled the measurement of SIF emission spectrum (Zhang et al., 2017). This progress promises to alleviate current limitations on the monitoring of terrestrial photosynthesis and opens up opportunities to fully exploit the use of the SIF spectrum as an indicator of the photosynthetic process (Verrelst et al., 2016).

In the process of radiative transfer in the vegetation, about $78 \%$ of the incident radiation is absorbed, while $11 \%$ is reflected from the leaf surface and $11 \%$ of the irradiation transmits through the leaf. Among the $78 \%$ absorbed light, about $20 \%$ is dissipated through heat and only about $2 \%$ is emitted as SIF, as a by-product of photosynthetic reactions occurring within the leaf itself. GPP is the amount of chemical energy as biomass produced in the photosynthetic reaction which uses about $56 \%$ of the incident radiation (Davidson et al., 2003). GPP is the main product of the photosynthesis process whereas SIF and heat can be considered as by-products of the process. These three (03) products and by-products are not generated separately but rather in competition with each other. As the generation of GPP and SIF arises from the same source of energy these two indicators of photosynthetic activity are related to each other. Several space-borne instruments such as the Fourier Transform Spectrometer (FTS) onboard the Japanese Greenhouse Gases Observing Satellite (GOSAT), the Global Ozone Monitoring Experiment-2 (GOME-2) onboard the European Metop-A and Metop-B, the Scanning Imaging Absorption spectrometer for Atmospheric Chartography (SCIAMACHY) onboard ENVISAT, the Orbiting Carbon Observatory-2 (OCO-2), and the Tropospheric Monitoring Instrument (TROPOMI) onboard Sentinel-5 Precursor (S5P) have been achieved global retrieval of global SIF at various wavelengths (Sun et al., 2018).

The OCO-2 satellite derived high-resolution SIF data offers new opportunity for the direct estimation of photosynthesis activity or GPP. Several studies demonstrate strong relationships between SIF and GPP over a 
variety of biomes based on OCO-2 SIF and tower GPP, suggesting that OCO-2 SIF has strong potential in deriving global GPP with higher resolution (Li et al., 2018a, 2018b; Wood et al., 2017; Verma et al., 2017). Some studies compare the OCO-2 SIF with retrievals from GOSAT and GOME-2 and examine its relationship with FLUXCOM and MODIS GPP datasets finding OCO-2 SIF robust and valuable for monitoring the global terrestrial GPP (Sun et al., 2017; 2018). The SIF-GPP relationships performs well in estimating GPP globally where GPP has been mapped based on global, OCO-2-based SIF product (GOSIF) and SIF-GPP relationships (Li and Xiao, 2019). Satellite-based SIF data with coarse spatial representativeness (around $0.5^{\circ}$ or coarser) are not appropriate to compare and validate with eddy covariance (EC) based GPP measurements. Despite 16-day revisiting schedule with a sparse sampling strategy, OCO-2 coverages have a high companion with EC site which results in positive correlation between SIF and GPP (Lu et al., 2018). The present study aims to check the reliability of this OCO-2 derived SIF data for the estimation of photosynthetic activity over comparatively small-scale area like Bangladesh by finding the relationship between OCO-2 derived SIF and MODIS derived GPP. This research infers the applicability of this OCO-2 derived SIF data for the comparatively accurate measurement of photosynthetic activity or GPP over small scale area like Bangladesh.

\section{MATERIALS AND METHODS}

SIF data used in this study were derived from OCO-2 that flies in a polar orbit with an equatorial crossing time of 1:35 pm (Verma et al., 2017; Hammerling et al., 2012). SIF in both Nadir and glint modes have been obtained from Level 2 V8 fluorescence data generated using IMAP-DOAS processing algorithm. The spatial and temporal resolution of this satellite is $1.29 \times 2.25 \mathrm{~km}^{2}$ and 16 days, respectively.

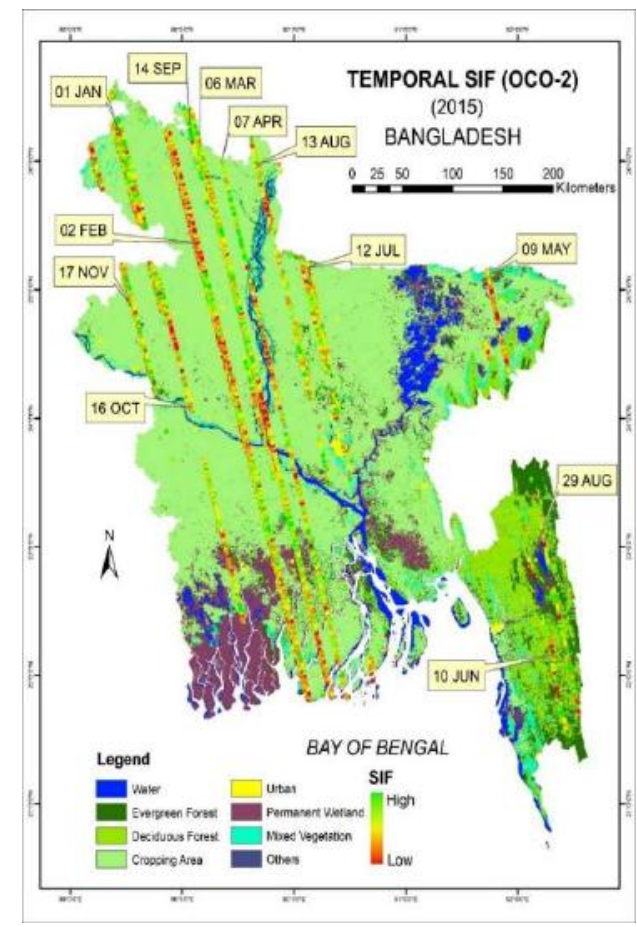

Figure 1: Temporal SIF of OCO-2 satellite showing sparse coverage in Bangladesh

The daily SIF "lite" files in NetCDF format of global SIF have been downloaded from https://mirador.gsfc. nasa.gov for the period of January to November 2015 and then extracted in the vicinity of the study area. This daily SIF data consists of given point's latitude, longitude, SIF at 757 and $771 \mathrm{~nm}$ and various other data flags. As the SIF signal at $757 \mathrm{~nm}$ is expected to be relatively stronger than at $771 \mathrm{~nm}$, this study uses the average of SIF values $757 \mathrm{~nm}$ and $771 \mathrm{~nm}$, with the latter multiplied by a factor of 1.5 (Verma et al., 2017; Sun et al., 2018).

The present study uses the Aqua MODIS data products instead of Terra MODIS since both Aqua MODIS satellite and OCO-2 satellite take measurements within 15 minutes from each other in nearly identical condition with comparable spatial resolution which facilitates integration of complementary measurements from MODIS and OCO-2 on different aspects of vegetation functions (Verma et al., 2017). MODIS Aqua GPP for the month of December 2015 is not available in the data platform, so that, from January 2015 to November 2015, only 12 common days SIF-GPP data have been analyzed for investigating the relationship. 
Table 1: Specification of the MODIS products

\begin{tabular}{lcc}
\hline Dataset & Spatial Resolution & Temporal granularity \\
\hline MODIS GPP (MYD17A2H) & $500 \mathrm{~m}$ & 8 - day composite \\
MODIS LAND COVER (MCD12Q1) & $500 \mathrm{~m}$ & Annual \\
\hline
\end{tabular}

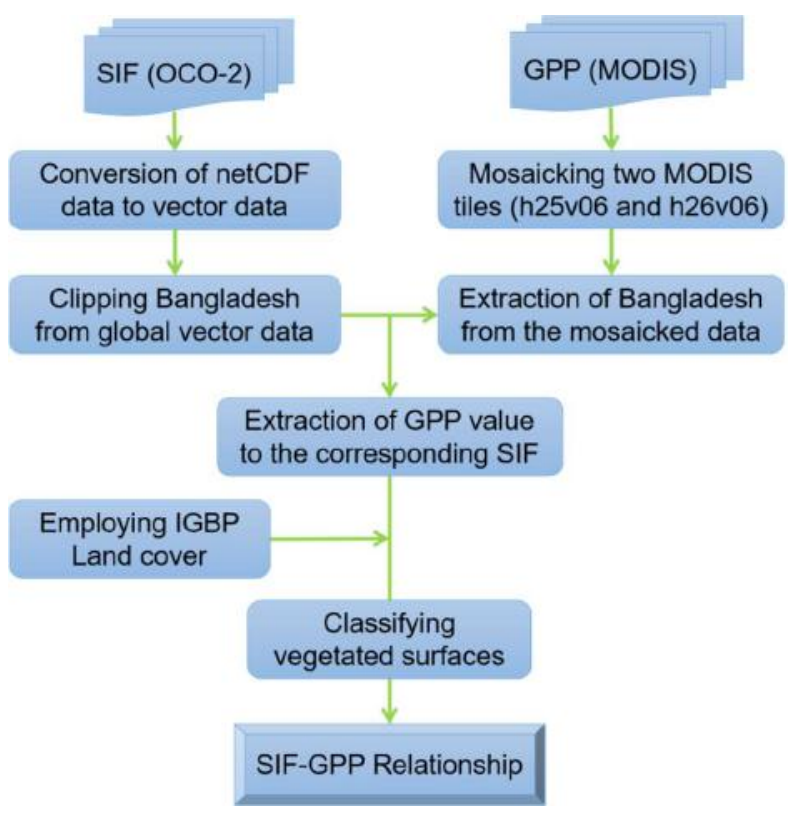

Figure 2: Flowchart of the methodology

MODIS Conversion Toolkit (MCTK) has been coupled in ENVI for the processing of MODIS products. ArcGIS software has been used as a common platform with a view to carrying out the analysis of the relationship between SIF and GPP along with the other parameters. There are three cloud flags of SIF data such as $0=$ Classified clear, $1=$ Processing failed and $2=$ not classified from which only the classified clear pixels were considered for the pixel-based analysis. As the present study focuses on the green elements of vegetation canopy, only the vegetated pixels such as Evergreen Forest (EF), Deciduous Forest (DF), Crop, and Mixed Vegetation (MV) from International Geosphere Biosphere Program (IGBP) index of land cover classification is accounted for analyses.

\section{RESULTS AND DISCUSSION}

In the present study, statistical analysis has been conducted between OCO-2 SIF and MODIS GPP under different ecosystems and different environmental conditions. The coefficient of determination $\mathrm{R}^{2}$ has been used to quantitatively describe the goodness of fit. The present study has carried out the SIF-GPP relationship with individual day pixel-based analysis.

January is the coldest and least humid month of Bangladesh when different vegetative local ecosystems are photosynthetically less active. In the Figure 1, it is noticeable that OCO-2 SIF has covered sparsely only in the northern part of Bangladesh where crop, mixed vegetation and urban pixels according to IGBP land cover types have been considered for the analysis. MV is showing comparatively higher correlations between SIF and GPP whereas Crop class shows weak correlation Figure 3a. On 02 February 2015, four types of land cover classes such as cropping area (Crop), EF, DF and MV have been found in OCO-2 track (Figure 1). Among this land cover types MV shows good correlation (Figure 3b). On 06 March, five types of land cover classes are found to analyze the relationship. Figure $3 \mathrm{c}$ shows moderate correlations between the parameters in terms of land classes. During the month of March, the solar irradiance is not so much. So that vegetation uses most of the absorbed solar energy in the photochemistry according to the demand for its photosynthesis process and the photosystems left low amount of absorbed energy that use to be re-emitted as SIF.

Spatial distortion in SIF footprints of OCO-2 accessed on 07 April 2015 whereas footprints on 06 March 2015 show ideal spatial distribution. The pixel dimension of OCO-2 is $1.29 \times 2.25 \mathrm{~km}^{2}$ which should be greater than MODIS pixel $\left(500 \times 500 \mathrm{~m}^{2}\right)$. But 07 April's footprint is exhibiting two or more pixels in one single MODIS pixel that is not reasonable (Figure 4). So that the plots of the SIF-GPP and the correlation curve shows meaningless pattern (Figure 3d). 

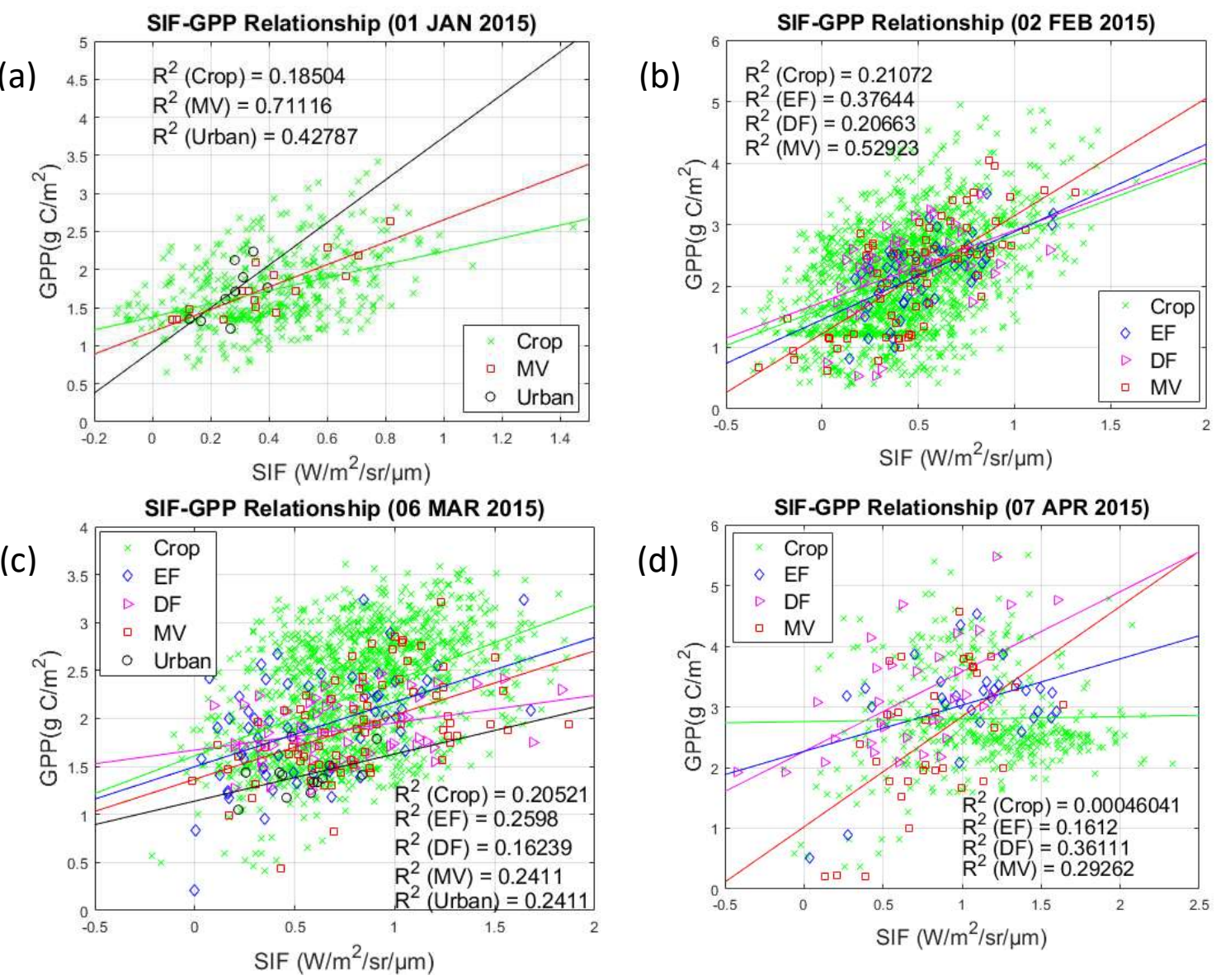

Figure 3: A SIF-GPP relationship under different land covers from January to April of 2015
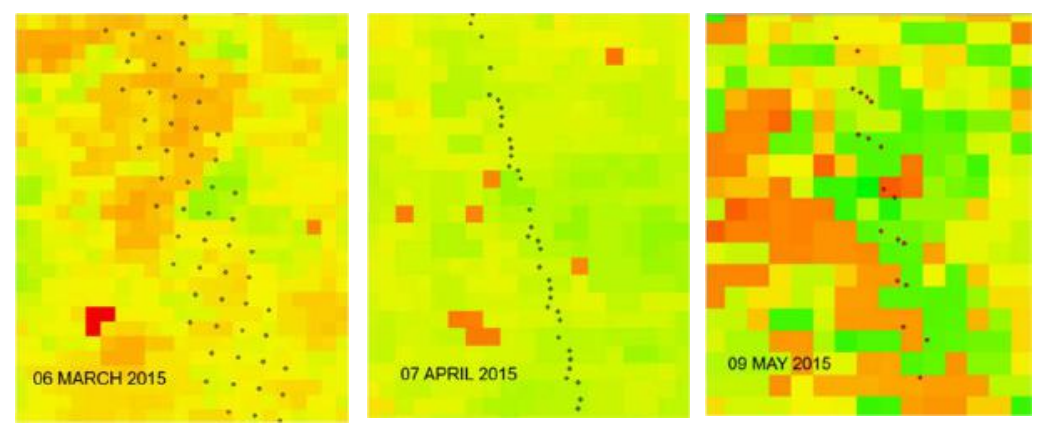

Figure 4: Spatial distortion in SIF retrieval of OCO-2 on 07 April and 09 May 2015 (middle and right) whereas it should be like 06 March 2015 (left). The background square pixels are of MODIS GPP and the dots are centers of OCO-2 SIF pixels

On 09 May 2015, same spatial distortion happens to OCO-2 footprints alike on 07 April 2017 as two or more center points of OCO-2 pixels are located in one single MODIS pixel (Figure 4). Such kind of spatial distortion results in haphazard scattering plot of SIF-GPP and meaningless correlation curve (Figure 5a). In June, Bangladesh experiences huge amount of rainfall due to water vapor carried out by monsoon wind from Bay of Bengal. On 10 June, OCO-2 SIF overpasses through south-eastern hilly region of Bangladesh where only DF land cover type is available. In this rainy season, the sky experiences cloud dominated atmosphere. Because of dense cloud, the irradiance decreases which results in the absorbed photosynthetically active radiation (APAR). The DF uses most of the absorbed solar energy in the photochemical reaction and the photosystems left very low absorbed energy which then re-emits as fluorescence. Hence, the good relationship between SIF and GPP is not found (Figure 5b). On 12 July 2015, OCO-2 overpasses through the middle part of Bangladesh where only 
cropland (Crop) land cover type is found. Here, the correlation of OCO-2 SIF with MODIS GPP is not good enough (Figure 5c). The discontinuous and sporadic distribution of OCO-2 footprints on 13 and 29 August 2015 (Figure 6) results in the correlation between SIF and GPP (Figure 5d).

On 14 September over northern-middle part of Bangladesh, only two land cover classes have been found among which both crop and evergreen forest show significant correlations (Figure 7b). On 16 October 2015, in SIF data only three land cover classes such as crop, evergreen forest and mixed vegetation have been found. Despite of not having enough strong correlation between SIF and GPP, both the parameters show higher intensity values. This indicates that vegetation receives more than enough Photosynthetically active radiation and soil moisture to accelerate the photochemical reaction for producing carbohydrate. Despite the use of Absorbed Photosynthetically Active Radiation, the photosystems still left enough absorbed energy which tends to be dissipated as Non-Photochemical Quenching (NPQ) and rest of the photon re-emits as SIF. Evergreen forest and mixed vegetation show significant relationship between SIF and GPP (Figure 7c). On 17 November, OCO-2 overpasses through northern part of Bangladesh with glint observation mode and very poor relation is observed between SIF and GPP (Figure 7d). According to cropping pattern of Bangladesh, November is the month of harvesting especially middle and northern part of Bangladesh. In this time most of northern cropland starts to be fellow after harvesting. This period also experiences lack of moisture and intensity of solar irradiance becomes lower which affect in the photosynthetic activity. The existing vegetation uses almost all the solar energy as fuel for photochemical reaction for producing GPP. So that, very low amount of absorbed energy remains in the photosystems to be re-emitted as fluorescence and no NPQ is active which ultimately results in very weak correlation between SIF and GPP (Meroni et al., 2009).

(a)

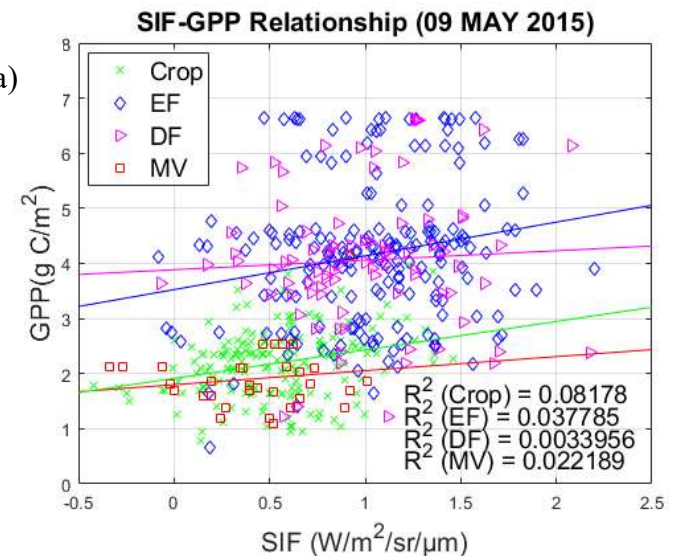

(c)

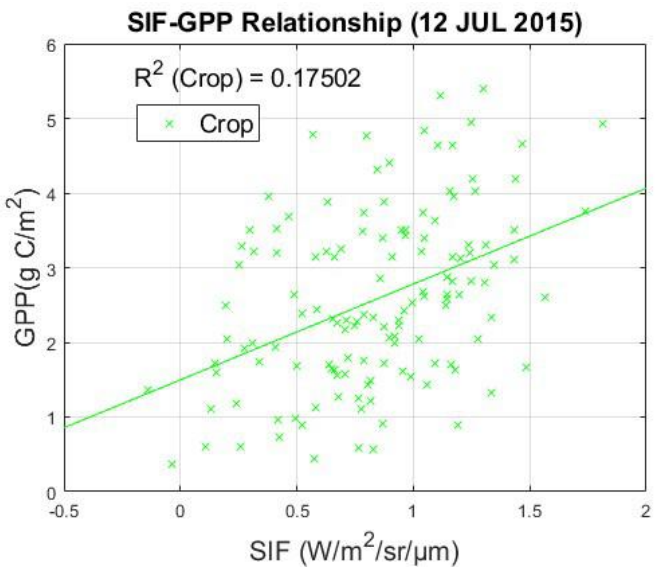

(b)

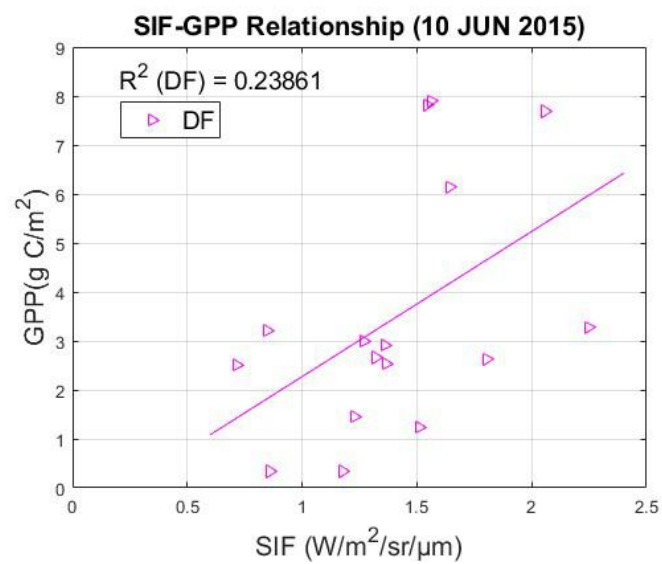

(d)

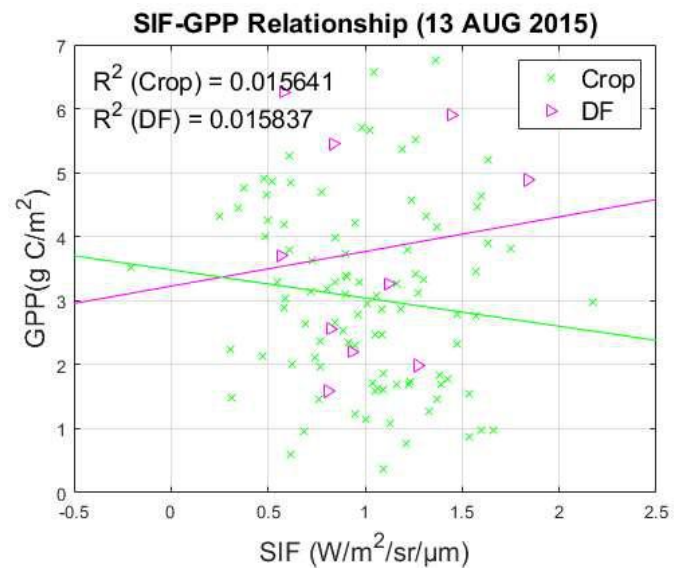

Figure 5: SIF-GPP relationships under different land covers from May to August of 2015

The present study tries to carry out the dynamics of the relationship between SIF and GPP temporally. This study has used SIF and GPP data of different dates of the year 2015. It was not possible to get the OCO-2 SIF data for the same point as the satellite data is characterized with narrow swath which is not repetitive exactly over the same points. Considering the spatial and temporal incongruity, the relationship between SIF and GPP in different land covers is not highly correlated but sometimes moderate relationship is found. 

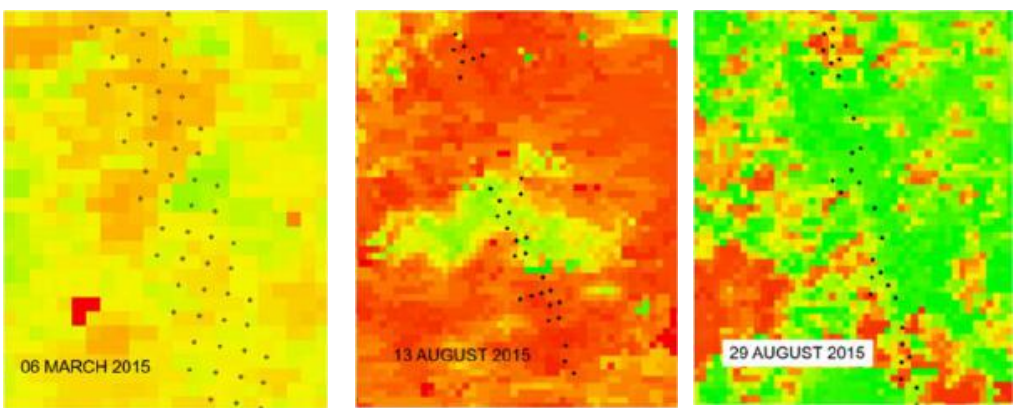

Figure 6: Spatial distortion in SIF retrieval of OCO-2 on 13 and 29 August 2015 (middle and right) whereas it should be like 06 March 2015 (left). The background square pixels are of MODIS GPP and the dots are centers of OCO-2 SIF pixels

(a)

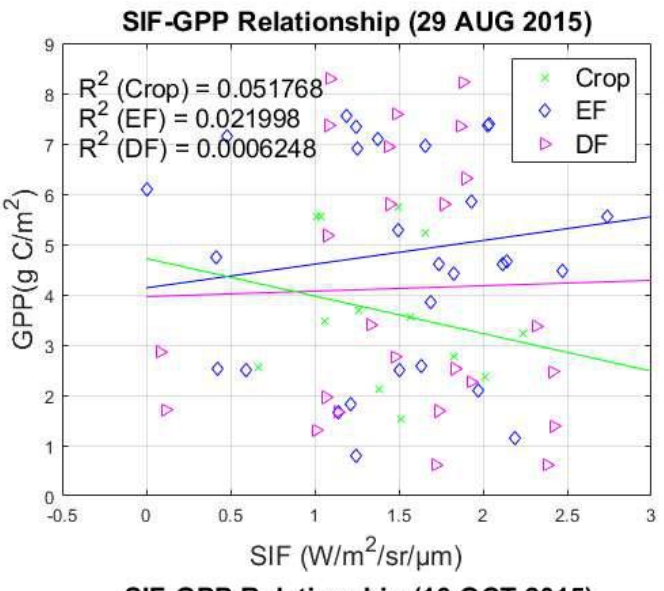

(c)

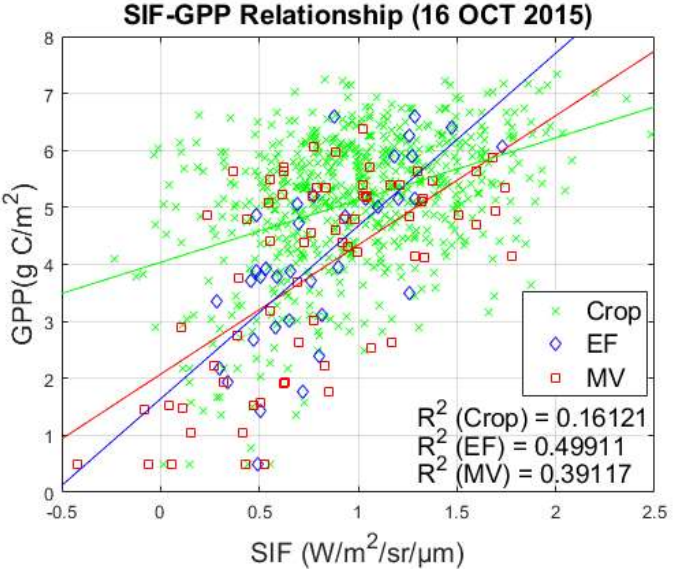

(b)

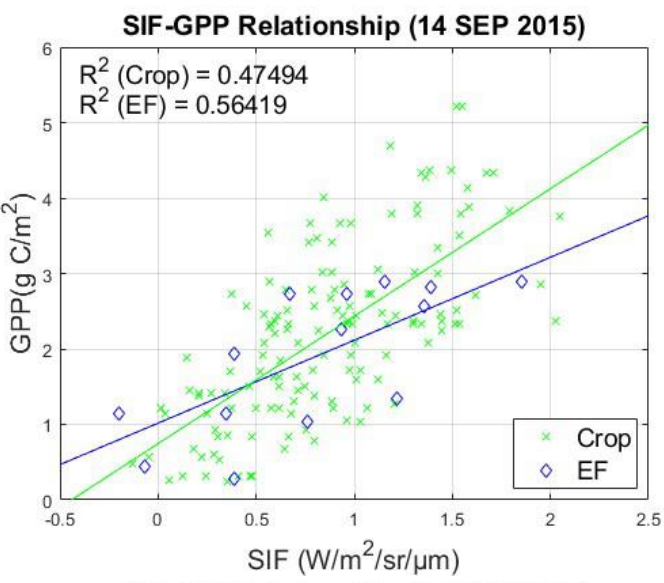

(d)

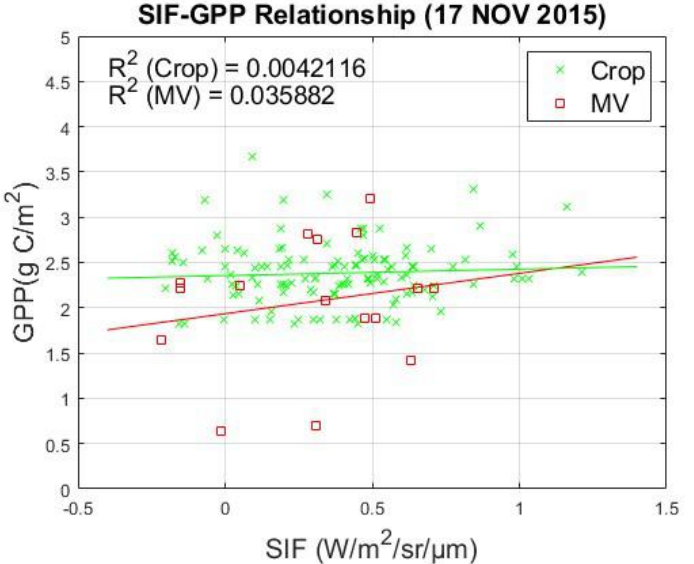

Figure 7: SIF-GPP relationship under different land covers from August to November of 2015

Most of the studies regarding the analysis of SIF and GPP relationship followed the global and monthly averaged spatiotemporal approach. The present study has chosen Bangladesh as the study area where there is no Eddy covariance (EC) based ground data. This study depends on the satellite derived GPP that is retrieved by MODIS sensor on board the Aqua satellite. Though the pixel sizes of both the satellites are comparable but pixel alignment of the pixels may impact in the SIF-GPP relationship as OCO-2 pixel is parallelogram whereas MODIS pixel is square in shape (Figure 8).

The study faces challenges in the consistency of OCO-2 SIF data spatially and temporally. Despite the improved spatial representativeness of OCO-2, it is noted that this satellite does not provide global continuous images as the MODIS provides and the daily coverage of OCO-2 is extremely limited with a sparse sampling strategy. 


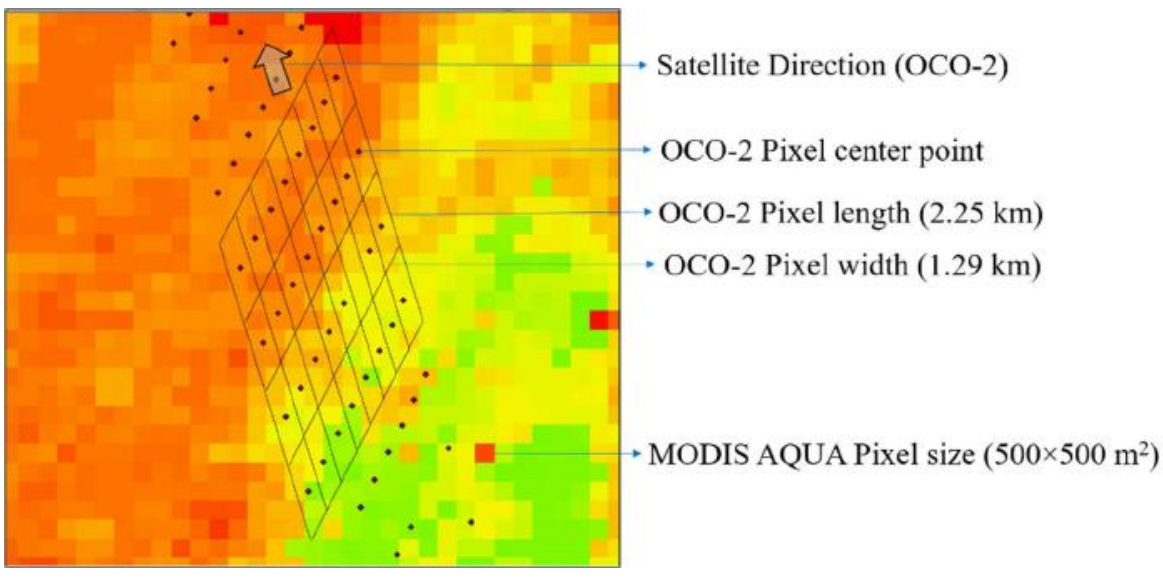

Figure 8: Pixel size and shape comparison of OCO-2 and MODIS Aqua satellites

\section{CONCLUSIONS}

The present study tries to carry out the dynamics of the relationship between SIF and GPP temporally. Though this study has taken SIF and GPP data of different dates but the OCO-2 SIF data is unavailable for the same point throughout the year since the satellite data is characterized with narrow swath which is not repetitive exactly over the same points. Considering the spatial and temporal incongruity, the relationship between SIF and GPP in different land covers shows moderate correlation for the month of January, February, March, September and October. Correlation between SIF and GPP is found poor for the month of April, May, June, July, August and November. Spatial distortion of OCO-2 SIF footprints may be responsible for poor correlation between SIF and GPP found in the month of April, May and August. Since multi-temporal SIF data is not available in respect to MODIS GPP, the characteristics of SIF-GPP relationship in a particular land cover is indistinct. So far, several studies have found positive correlations between SIF and GPP in specific conditions, but most of those studies use EC tower-based data and analyses was performed for large spatiotemporal scale. The expansion of EC network especially along the satellite tracks will ease the challenges in estimating photosynthetic activity based on satellite-derived SIF.

\section{REFERENCES}

Cui, T., Sun R., and Qiao C., 2017. Analyzing the relationship between solar-induced chlorophyll fluorescence and gross primary production using remotely sensed data and model simulation. Int. J. Earth. Environ. Sci., 2(129). https://doi.org/10.15344/2456-351X/2017/129

Davidson, M., Berger M., Moya I., Moreno J., Laurila T., Stoll M.P., and Miller J., 2003. Mapping photosynthesis from space-a new vegetation-fluorescence technique, ESABu, 116, 34-37.

Hammerling, D.M., Michalak A.M., and Kawa S.R., 2012. Mapping of CO2 at high spatiotemporal resolution using satellite observations: Global distributions from OCO-2, J. Geophys. Res. Atmos., 117(D6). https://doi.org/10.1029/2011JD017015

Li, X., Xiao J., and He B., 2018a. Chlorophyll fluorescence observed by OCO-2 is strongly related to gross primary productivity estimated from flux towers in temperate forests, Remote Sens. Environ., 204, 659671.

Li, X., Xiao J., He B., Altaf Arain M., Beringer J., Desai A. R., Emmel C., Hollinger D. Y., Krasnova A., Mammarella I., Noe S. M., Ortiz P. S., Rey-Sanchez A. C., Rocha A. V., and Varlagin A., $2018 \mathrm{~b}$. Solar-induced chlorophyll fluorescence is strongly correlated with terrestrial photosynthesis for a wide variety of biomes: First global analysis based on OCO-2 and flux tower observations, Glob. Chang. Biol., 24(9), 3990-4008.

Li, X., and Xiao J., 2019. Mapping photosynthesis solely from solar-induced chlorophyll fluorescence: A global, fine-resolution dataset of gross primary production derived from OCO-2, Remote Sens., 11(21), 2563.

Lu, X., Cheng X., Li X., and Tang J., 2018. Opportunities and challenges of applications of satellite-derived sun-induced fluorescence at relatively high spatial resolution, Sci. Total Environ., 619, 649-653.

Meroni, M., Rossini M., Guanter L., Alonso L., Rascher U., Colombo R., and Moreno J., 2009. Remote sensing of solar-induced chlorophyll fluorescence: Review of methods and applications, Remote Sens. Environ., 13(10), 2037-2051. https://doi.org/10.1016/j.rse.2009.05.003 
Sun, Y., Frankenberg C., Wood J. D., Schimel D. S., Jung M., Guanter L., Drewry D. T., Verma M., PorcarCastell A., Griffis T. J., Gu L., Magney T. S., Köhler P., Evans B., and Yuen K., 2017. OCO-2 advances photosynthesis observation from space via solar-induced chlorophyll fluorescence. Sci., $358(6360)$.

Sun, Y., Frankenberg C., Jung M., Joiner J., Guanter L., Köhler P., and Magney T., 2018. Overview of SolarInduced chlorophyll Fluorescence (SIF) from the Orbiting Carbon Observatory-2: Retrieval, crossmission comparison, and global monitoring for GPP, Remote Sens. Environ., 209, 808-823. https://doi.org/10.1016/j.rse.2018.02.016

Verma, M., Schimel D., Evans B., Frankenberg C., Beringer J., Drewry D.T., Magney T., Marang I., Hutley L., Moore C., and Eldering A., 2017. Effect of environmental conditions on the relationship between solarinduced fluorescence and gross primary productivity at an OzFlux grassland site, J. Geophys. Res. Biogeosci., 122(3), 716-733. https://doi:10.1002/2016JG003580.

Verrelst, J., van der Tol C., Magnani F., Sabater N., Rivera J.P., Mohammed G., and Moreno J., 2016. Evaluating the predictive power of sun-induced chlorophyll fluorescence to estimate net photosynthesis of vegetation canopies: A SCOPE modeling study, Remote Sens. Environ., 176, 139-151. https://doi.org/10.1016/j.rse.2016.01.018

Wood, J. D., Griffis T. J., Baker J. M., Frankenberg C., Verma M., and Yuen K., 2017. Multiscale analyses of solar-induced florescence and gross primary production, Geophys. Res. Lett., 44(1), 533-541.

Zhang, Y., Guanter L., Berry J.A., Joiner J., van der Tol C., Huete A., Gitelson A., Voigt M., and Köhler P., 2014. Estimation of vegetation photosynthetic capacity from space-based measurements of chlorophyll fluorescence for terrestrial biosphere models, Glob. Chang. Biol., 20(12), 3727-3742. https://doi: $10.1111 / \mathrm{gcb} .12664$

Zhang, Y., Xiao X., Wu X., Zhou S., Zhang G., Qin Y., and Dong J., 2017. A global moderate resolution dataset of gross primary production of vegetation for 2000-2016, Sci. Data, 4(170165). DOI:10.1038/sdata. 2017.165

(C) 2020 The Authors. Journal of Engineering Science published by Faculty of Civil Engineering, Khulna University of Engineering \& Technology. This is an open access article under the terms of the Creative Commons AttributionNonCommercial-NoDerivatives License, which permits use and distribution in any medium, provided the original work is properly cited, the use is non-commercial and no modifications or adaptations are made. 